WwW.ijbas.com

\title{
CURRENT TRENDS OF MEDICAL DEVICE REGULATION IN AUSTRALIA
}

\section{MEGHANA D*, KOUSHIK Y AND RAMA RAO N}

Department of Pharmaceutical Regulatory Affairs, Chalapathi Institute of Pharmaceutical Sciences, Lam, Guntur-522034

*Corresponding Author: Meghana Dandamudi: E Mail: dandamudimeghana07@gmail.com

Received 22 ${ }^{\text {nd }}$ Feb. 2021; Revised 20 ${ }^{\text {th }}$ Mar. 2021; Accepted $19^{\text {th }}$ April. 2021; Available online $1^{\text {st }}$ Dec. 2021 $\underline{\text { https://doi.org/10.31032/IJBPAS/2021/10.12.5779 }}$

\section{ABSTRACT}

With Increased use of medical devices, strict regulatory standards are required to ensure that devices are safe, well-studied and have the least adverse reactions. The updated TGA guidelines and the legislative amendment provide adequate guidance for both manufacturers and the competent authorities to manage cases effectively and in an appropriate manner. These guidelines shall be updated annually according to the schedule, which provides a high level of encouragement in the research of medical devices, as is currently the case. Pharmacy staff can certainly play an important role in the regulation of medical devices. The safety, risks, effectiveness and performance of medical devices must be well established and properly regulated. It is hoped that the guidelines will be implemented and properly regulated with an effective outcome.

Keywords: Medical devices, Adverse reactions, TGA Guidelines, Manufacturers \section{INTRODUCTION}

Medical devices in Australia are regulated by the Therapeutic Goods Administration $\{\mathrm{TGA}\}$, which is part of the Australian Government Department of Health and Aging. The Therapeutic Goods Administration $\{\mathrm{TGA}\}$ administers the
Therapeutic Goods ACT [1989] by applying a risk management approach designed to ensure that the therapeutic goods supplied in Australia comply with acceptable standards of quality and safety $[\mathbf{1}, \mathbf{2}]$. 
As per TGA medical devices, a wide range of products are defined, such as medical gloves, bandages, syringes, blood pressure monitors and X-ray equipment. They generally have a physical or mechanical effect on the body or are used to monitor the body and its function.

\section{METHODOLOGY}

\section{Essential Principles [3, 4]}

Part of these requirements includes six general principles that all devices must comply with. These relate to health and safety, including long-term safety, with a view to ensuring that the benefits outweigh the risks. A further nine design and construction principles apply to devices on a case-by-case basis.

Proper compliance with these principles ensures that the devices are as safe as possible and perform as intended. Once the device has been approved, it is expected that the manufacturer will continue to monitor the performance and safety of its device and ensure that it continues to comply with the essential principles.

\section{Classification of medical devices [6, 7]}

The TGA has adopted a system of classification of devices based on the level of risk. The lowest risk medical devices, Class-I devices, are not assessed by the TGA prior to inclusion in the ARTG \{Australian Register of Therapeutic Goods\}. Classification of medical devices are mentioned in Figure 1.

Marketing Regulation of Medical devices [8]

Life cycle approach for medical device regulation is mentioned in Figure 2.

* Pre market regulation of medical devices [8]

- The manufacture shall apply the appropriate uniformity assessment procedure.

- Manufacturers making an Australian declaration of conformity - a legal declaration that all the required evidence exists and that the device complies with Australian regulatory requirements.

- The Australian sponsor shall submit evidence of the manufacturer's conformity assessment to the TGA to all devices. (Except for Class-I devices which are not sterile or do not have a measuring function)

- The TGA to evaluate the available evidence for high-risk devices

- Devices to be included in the ARTG

* Post market regulation of medical devices [8]

- The manufacturer shall maintain the current evidence of conformity assessment to support the device. 
- The manufacturer shall monitor ongoing performance, safety and inform the TGA if there are serious issues.

- The TGA conducts random and targeted assessments of the medical devices included in the ARTG

* Risk based regulation of medical devices [13]

The TGA has a risk-based approach to the regulation of medical devices. Accordingly, the scope of the regulation depends on
- The intended purpose of the device.

- The degree of risk that the device poses to the patient.

- The degree of risk that the device poses to the user and those in the vicinity

- Whether the device is used internally or externally by the patient

- The duration of use.

\section{Pacemakers, cochlear implants}

Active

Implantab

-le Medical

Devices
Elastic bandages, Tongue depressors, cervical collars, slings, Non sterile dressings.

CLASS-I

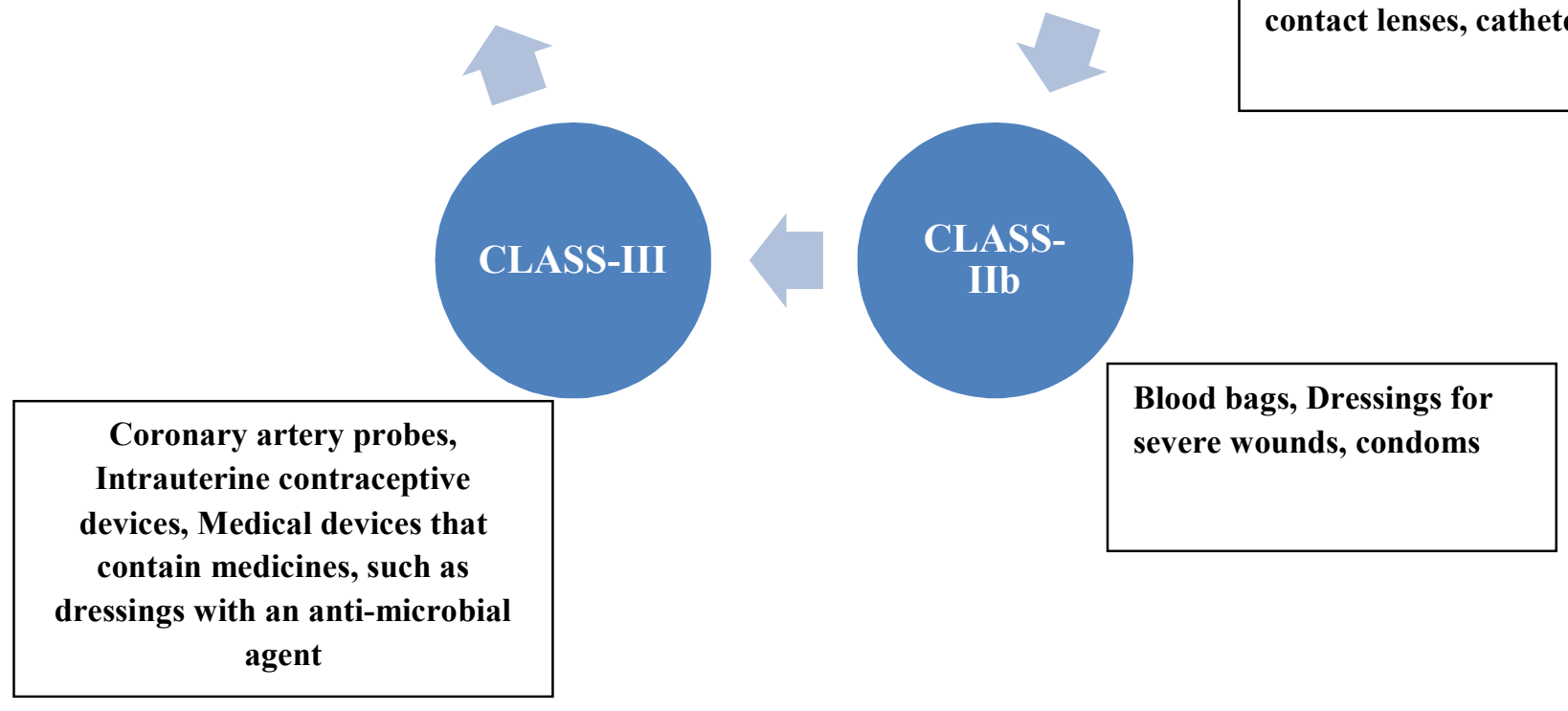

Figure 1: Classification of medical devices [6, 7] 


\section{PREMARKET REGULATION OF MEDICAL DEVICES}

\section{POST MARKET REGULATION OF MEDICAL DEVICES}

\section{RISK BASED REGULATION OF MEDICAL DEVICES}

Figure 2: Life Cycle Approach for Regulation of Medical Devices [5]

Table 1: Annual charges in TGA regulations 2018 [9]

\begin{tabular}{|c|c|c|}
\hline Class of medical devices & Charge & Regulation \\
\hline AIMD & $\$ 1,180$ & Item 7(4) (d) \\
\hline Class III & $\$ 1,180$ & Item 7(4) (d) (4) (c) \\
\hline Class IIb & $\$ 920$ & Item 7 (4) (c) \\
\hline Class IIa & $\$ 920$ & Item 7 (4) (b) \\
\hline Class I sterile & $\$ 630$ & Item 7 (4) (b) \\
\hline Class-I Measuring Function & $\$ 630$ & Item 7 (4) (a) \\
\hline
\end{tabular}

\section{CONCLUSION}

The objective of present work is to know the current trends of medical device regulation in Australia which are regulated by Therapeutic Goods Administration [TGA]. The current regulations are complied with the essential principles developed under TGA. The main goal of TGA is to monitor the safety and effectiveness of medical device. TGA has undergone for many revisions and developed many regulations to monitor the safety and effectiveness of medical devices.

\section{REFERENCES}

[1] https://www.emergobyul.com/resourc es/market-australia
[2] https://www.goldsteinresearch.com/re port/australia-medical-devicesmarket-size

[3] https://www.tga.gov.au/medicaldevices-overview

[4] https://www.tga.gov.au/sites/default/f iles/presentation-trends-in-australianand-international-regulation-andregulatory-cooperation.pdf

[5] https://www.tga.gov.au/presentationlife-cycle-medical-devices

[6] https://www.tga.gov.au/sites/default/f iles/devices-argmd-01.pdf

[7] https://www.tga.gov.au/smeassist/what-classification-mymedical-device 
[8] https://www.tga.gov.au/publication/a ustralian-regulatory-guidelinesmedical-devices-argmd

[9] https://www.tga.gov.au/bookpage/medical-devices-2\#sponsor-appfees

[10] https://2016.export.gov/industry/hea 1th/healthcareresourceguide/eg_mai n_108561.asp

[11] https://www.healthdirect.gov.au/part ners/tga-therapeutic-goodsadministration

[12] https://www.nps.org.au/australianprescriber/articles/what-does-tgaapproval-of-medicines-mean

[13] https://en.wikipedia.org/wiki/Therap eutic_Goods_Administration

[14] https://www.tga.gov.au/smeassist/medical-devices-regulationintroduction 